\title{
Assessment of telomerase activity in leukocytes of type 2 diabetes mellitus patients having or not foot ulcer: Possible correlation with other clinical parameters
}

\author{
DIMITRIOS BALTZIS ${ }^{1,2}$, EVANGELIA MEIMETI ${ }^{3}$, MARIA G. GRAMMATIKOPOULOU ${ }^{4}$, MATTHIEU ROUSTIT ${ }^{5}$, \\ ELENI MAVROGONATOU ${ }^{6}$, DIMITRIS KLETSAS ${ }^{6}$, SMARAGDA EFRAIMIDOU $^{7}$, CHRISTOS MANES $^{1}$, \\ TAXIARCHIS K. NIKOLOUZAKIS ${ }^{8}$, JOHN TSIAOUSSIS ${ }^{8}$, ARISTIDES M. TSATSAKIS ${ }^{9}$, \\ DEMETRIOS A. SPANDIDOS ${ }^{10}$, CHRISTINA-MARIA TRAKATELLI ${ }^{2}$ and NIKOLAOS DRAKOULIS ${ }^{3}$
}

\begin{abstract}
${ }^{1}$ Diabetes Center; ${ }^{2}$ Third Department of Internal Medicine, Papageorgiou General Hospital, 56403 Thessaloniki;
${ }^{3}$ Research Group of Clinical Pharmacology and Pharmacogenomics, Faculty of Pharmacy, School of Health Sciences, National and Kapodistrian University of Athens, 15771 Athens; ${ }^{4}$ Department of Nutrition and Dietetics, Alexander Technological Educational Institute, 57400 Thessaloniki, Greece; ${ }^{5} \mathrm{HP} 2$ Laboratory, University of Grenoble Alpes, 38700 La Tronche Université Grenoble Alpes, France; ${ }^{6}$ Laboratory of Cell Proliferation and Ageing, Institute of Biosciences and Applications, National Centre for Scientific Research 'Demokritos', 15341 Athens; ${ }^{7}$ Department of Hematology, Papageorgiou General Hospital, 56403 Thessaloniki; ${ }^{8}$ Laboratory of Anatomy-Histology-Embryology, ${ }^{9}$ Department of Forensic Sciences and Toxicology, ${ }^{10}$ Laboratory of Clinical Virology,
\end{abstract}

Medical School, University of Crete, 71003 Heraklion, Greece

Received September 20, 2017; Accepted December 25, 2017

DOI: $10.3892 /$ etm.2018.5798

\begin{abstract}
Telomerase is the enzyme that maintains telomere length by adding telomeric repeats after each cell division. Numerous metabolic factors such as obesity, insulin resistance or physical inactivity have been associated with shortened telomeres. In the present study, we assessed telomerase activity in diabetic patients having or not foot ulcer. A total of 90 adult patients with type 2 diabetes mellitus (T2DM) were studied. Patients were allocated into two groups according to the absence or presence of active foot ulcers as follows: Non-ulcer group $(\mathrm{N}=58)$ and ulcer group $(\mathrm{N}=32)$. Our data revealed that the patients with diabetic ulcers had significantly greater waist circumference and neuropathy disability score, while exhibiting lower telomerase activity, indicating the possible existence of a common clinical profile among ulcer-bearing diabetic patients.
\end{abstract}

Correspondence to: Dr Nikolaos Drakoulis, Research Group of Clinical Pharmacology and Pharmacogenomics, Faculty of Pharmacy, School of Health Sciences, National and Kapodistrian University of Athens, Panepistimiopolis, Zografou, 15771 Athens, Greece

E-mail: drakoulis@pharm.uoa.gr

Abbreviations: T2DM, type 2 diabetes mellitus; DPN, diabetic peripheral neuropathy; NDS, neuropathy disability score; TC, total cholesterol; TG, triglycerides; HDL, high-density lipoprotein; LDL, low-density lipoprotein; BMI, body mass index; PCR, polymerase chain reaction

Key words: diabetic peripheral neuropathy, neuropathy disability score, oxidative damage, telomere-diabetes
Validation of our findings by extending the study in larger patient groups may contribute to the understanding of T2DM pathophysiology and its main clinical implications.

\section{Introduction}

Telomeres are nucleoprotein structures at the end of linear chromosomes containing repetitive DNA sequences (TTAGGG in vertebrates). Their role is to protect chromosome ends from deterioration or fusion with adjacent chromosomes, thus preventing incomplete replication and maintaining protein coding and regulatory elements of the genome $(1,2)$. The enzyme telomerase prevents telomeres from shortening by adding telomeric repeats (2). Several factors, such as increasing age, disease and mortality, have been associated with reduced telomere length $(3,4)$. Telomeric DNA is particularly prone to oxidative damage at the GGG sequence, since exposure to free radicals or oxidants causes DNA damage, including single-strand breaks $(5,6)$. On the other hand, diabetes and metabolic syndrome are associated with oxidative stress (7-9).

Given that a variety of metabolic factors such as obesity $(10,11)$, insulin resistance (12) or physical inactivity (13) have been associated with shortened telomeres, the relationship between type 2 diabetes mellitus (T2DM) and telomerase activity is an issue of intense investigation (14). Today we are in a position to acknowledge a bilateral telomere-diabetes relationship: shorter telomeres may lead to impaired insulin secretion and glucose tolerance in mouse pancreatic $\beta$-cells, while chronic hyperglycemia leading to increased oxidative stress attenuates telomerase activity of human leukocytes, results in a reduced telomere length (14-16). As a consequence, 
T2DM patients demonstrate shortened telomeres $(16,17)$, with several macro- and micro-vascular complications due to chronic hyperglycemia, such as retinopathy, nephropathy or vascular aging (18-20).

High percentages of patients diagnosed with T2DM have been reported to develop nerve damage (neuropathy), which leads to vascular damage, ulcers and amputation $(21,22)$. Recently, it has been shown that diabetic peripheral neuropathy (DPN) is strongly associated with the risk for myocardial infraction (23). Taking into account that ulcers constitute a major complication of T2DM, the aim of the current study was to assess specific clinical traits, including telomerase activity and neuropathy disability score (NDS), in T2DM patients with or without ulcer.

\section{Materials and methods}

The study was conducted in 90 adult patients with T2DM from the Diabetes Mellitus Outpatient Clinic of the 3rd Department of Internal Medicine of Papageorgiou General Hospital in Thessaloniki, Greece. The protocol of the study was approved by the Ethics Committee of Papageorgiou General Hospital and patients provided their informed consent prior to participation complying with the requirements of the Declaration of Helsinki.

Inclusion criteria were the following: Males and females ( $>18$ years of age) with confirmed T2DM diagnosis according to the ADA/IDF criteria (24). Patients having a history of myocardial infarction, stroke, coronary revascularization, cardiac bypass, active or chronic liver or renal disease, lumbar/cervical discopathy, carpal tunnel syndrome, alcohol abuse, inherited neuropathy and vitamin B9/B12 deficiency and patients diagnosed for any autoimmune disease, HIV infection, malignancies, primary neurologic disorders, including previous spinal injury, were excluded. The use of glucocorticoid-, isoniazid- or metronidazole-containing drugs was an extra exclusion criterion. Patients were stratified into a non-ulcer $(\mathrm{N}=58)$ and an ulcer $(\mathrm{N}=32)$ group based on the absence or presence of active foot ulcers located below the ankle joint.

Fasting blood samples were collected for the assessment of blood lipid levels, including total cholesterol (TC), triglycerides (TG), high-density lipoprotein (HDL) and low-density lipoprotein (LDL), as well as of glycated haemoglobin (HbAlc) and creatinine levels. Body weight, stature and waist circumference were measured for each patient and body mass index (BMI) was calculated.

DPN was evaluated by using the NDS after testing the sensations of pain, touch, cold, and vibration on both legs of the patient and assigning a score according to the level of impaired sensation. An NDS $\geq 5$ was indicative of DPN $(23,25)$.

Telomerase activity assay was performed in the pellets of white blood cells resuspended with CHAPS lysis buffer using the TRAPeze RT Telomerase Detection kit S7710 (Merck KGaA, Darmstadt, Germany), according to the manufacturer's instructions. In detail, the pellets were thawed, resuspended with $200 \mu \mathrm{l} \mathrm{CHAPS}$ and incubated for $30 \mathrm{~min}$ on ice. Samples were centrifuged at $12,000 \mathrm{x}$ for $20 \mathrm{~min}$ at $4^{\circ} \mathrm{C}$ and the supernatant was aliquoted, snap-frozen in liquid nitrogen and stored at $-80^{\circ} \mathrm{C}$ until analysis. Samples were further diluted 200 -fold and used for the TRAPeze RT Telomerase assay along with a positive control (a telomerase-positive extract provided by the manufacturer also diluted in $200 \mu \mathrm{l}$ CHAPS), a minus telomerase control (only CHAPS lysis buffer) and a no template control (only nuclease-free water). Heat-treated samples at $85^{\circ} \mathrm{C}$ for $10 \mathrm{~min}$ also served as negative controls. Polymerase chain reaction (PCR) amplification was performed in $25 \mu 1$ reactions using $2 \mu \mathrm{l}$ of sample and 2 units of Titanium Taq DNA Polymerase (Takara Bio, Inc., Otsu, Japan) following the manufacturer's protocol. Telomerase activity was calculated using the generated TSR8 standard curve deduced from TSR8 known concentrations always included in each assay. Protein content was determined with the Protein Determination kit (Cayman Chemical Co., Ann Arbor, MI, USA) and telomerase activity was normalized to $\mu \mathrm{g}$ of protein.

Statistical analysis. Statistical analysis was performed with Statgraphics Centurion software (Statgraphics Technologies, Inc., The Plains, VA,USA). Data were expressed as means \pm standard deviation (means \pm SD) or as medians \pm standard error of the mean (medians \pm SEM) when lacking normality in their distribution. Between-group comparisons were performed with ANOVA, followed by post-hoc comparisons performed with Tukey's test or the non-parametric Kruskal-Wallis test for normal and not normal distributions, respectively. Differences were considered significant for $\mathrm{P}<0.05$.

\section{Results}

Several clinical characteristics of T2DM patients without or with foot ulcers are presented in Table I. The clinical characteristics that were evaluated can be grouped as follows: Demographic characteristics (age and sex), well appreciated risk factors (waist circumference, BMI, smoking history, TC, TG, HDL and LDL levels), prognostic factors (diabetes duration, HbA1c, creatinine levels, NDS) and leukocytes' telomerase activity. Among the clinical characteristics investigated here only waist circumference, NDS and leukocytes' telomerase activity demonstrated statistically significant differences between the two patient groups $(\mathrm{P}<0.05)$.

In Fig. 1, a graphical representation of the statistical analysis for all clinical parameters tested in the present study between the non-ulcer and ulcer groups is depicted. It is evident that, T2DM patients of the current study with foot ulcer were characterized by a significantly greater waist circumference $(\mathrm{P}=0.0382)$ and a significantly higher NDS $\left(\mathrm{P}=9.09 \times 10^{-8}\right)$, accompanied by a significantly lower leukocyte telomerase activity $(\mathrm{P}=0.0261)$ when compared to the non-ulcer T2DM patients. No other clinical parameters assessed in the present study were statistically different between the two groups of diabetic patients.

\section{Discussion}

Diabetic patients who have developed ulcers or have even undergone amputations seem to have a lower life expectancy, which may reach up to $70 \%$ (26). On the other hand, short telomere length associated with low telomerase activity has been reported to be an indicator for decreased life expectancy (27). 
Table I. Clinical charasteristics of participants allocated to two groups according to the absence or presence of diabetic ulcers.

\begin{tabular}{|c|c|c|c|c|}
\hline Characteristic & Total $(\mathrm{N}=90)$ & Non-ulcer $(\mathrm{N}=58)$ & Ulcer $(\mathrm{N}=32)$ & P-value ${ }^{a}$ \\
\hline Age (years) & $66.0 \pm 9.2$ & $65.3 \pm 9.3$ & $67.4 \pm 8.8$ & 0.2936 \\
\hline $\operatorname{Sex}(\mathrm{M} / \mathrm{W})$ & $55 / 35$ & $35 / 23$ & 20/12 & \\
\hline Diabetes duration (years) & $14.0 \pm 1.0$ & $12.0 \pm 1.2$ & $16.0 \pm 1.3$ & 0.0683 \\
\hline Waist circumference $(\mathrm{cm})$ & $109.1 \pm 12.7$ & $107.1 \pm 13.2$ & $112.8 \pm 10.8$ & 0.0382 \\
\hline $\operatorname{BMI}\left(\mathrm{kg} / \mathrm{m}^{2}\right)$ & $31.3 \pm 0.7$ & $30.8 \pm 0.8$ & $31.2 \pm 1.0$ & 0.0674 \\
\hline Smoking history (Y/N) & $17 / 73$ & $12 / 46$ & $5 / 27$ & \\
\hline $\mathrm{TC}(\mathrm{mg} / \mathrm{dl})$ & $181.3 \pm 39.0$ & $181.8 \pm 34.4$ & $176.6 \pm 44.1$ & 0.8702 \\
\hline TG (mg/dl) & $127.0 \pm 7.8$ & $116.5 \pm 9.5$ & $121.0 \pm 10.3$ & 0.5722 \\
\hline HDL (mg/dl) & $43.0 \pm 1.1$ & $44.0 \pm 1.2$ & $44.0 \pm 1.7$ & 0.4887 \\
\hline LDL (mg/dl) & $103.5 \pm 3.7$ & $102.5 \pm 3.9$ & $105.0 \pm 5.3$ & 0.8232 \\
\hline HbA1c (\%) & $7.1 \pm 0.1$ & $7.1 \pm 0.1$ & $7.1 \pm 0.2$ & 0.2672 \\
\hline Creatinine (mg/dl) & $0.9 \pm 0.1$ & $0.9 \pm 0.1$ & $0.9 \pm 0.0$ & 0.9696 \\
\hline NDS & $10 \pm 0.6$ & $5.0 \pm 0.7$ & $11.0 \pm 0.5$ & $9.09 \times 10^{-8}$ \\
\hline Telomerase activity (AU) & $1,275.2 \pm 156.8$ & $1,573.3 \pm 219.7$ & $1,146.7 \pm 175.5$ & 0.0261 \\
\hline
\end{tabular}

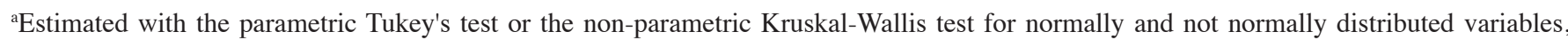
respectively. BMI, body mass index; TC, total cholesterol; TG, triglycerides; HDL, high-density lipoprotein; LDL, low-density lipoprotein; NDS, neuropathy disability score; AU, arbitrary units.

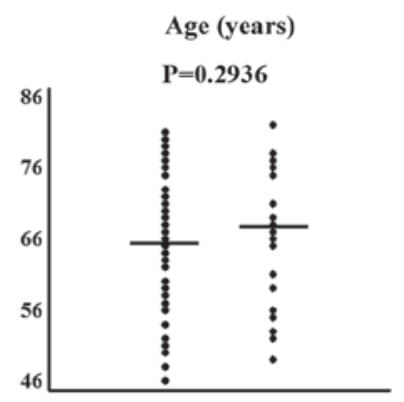

$\mathrm{TC}(\mathrm{mg} / \mathrm{dl})$
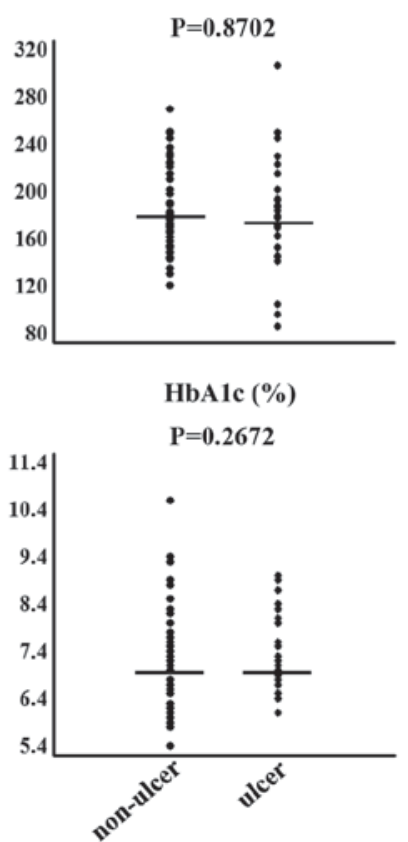

Diabetes duration (years)

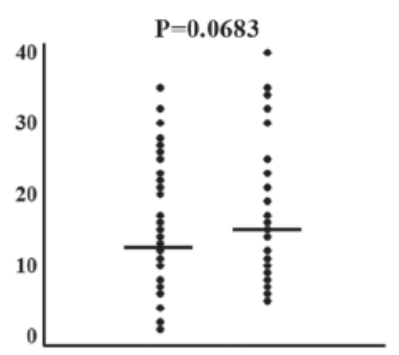

TG $(\mathrm{mg} / \mathrm{dl})$
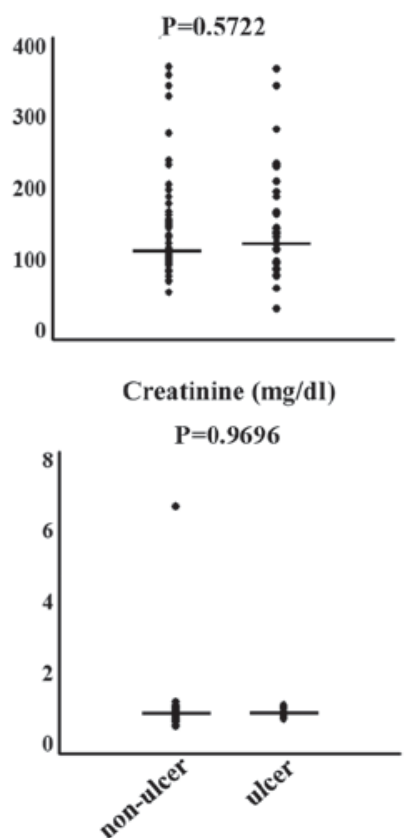

Waist circumference $(\mathrm{cm})$

$\mathrm{P}=\mathbf{0 . 0 3 8 2}$

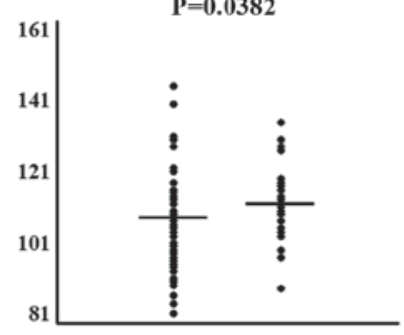

HDL $(\mathrm{mg} / \mathrm{dl})$

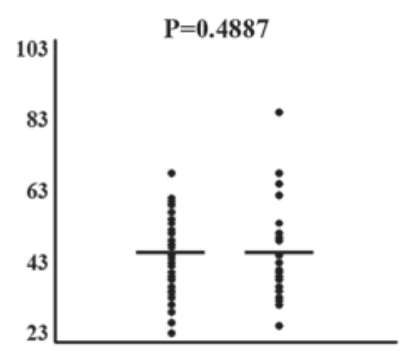

NDS

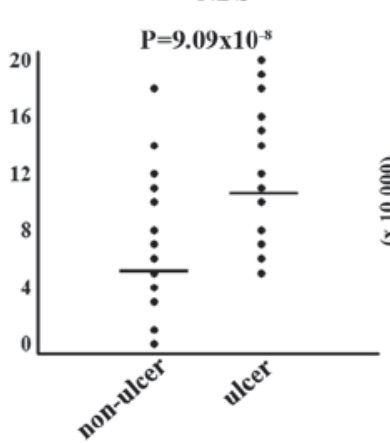

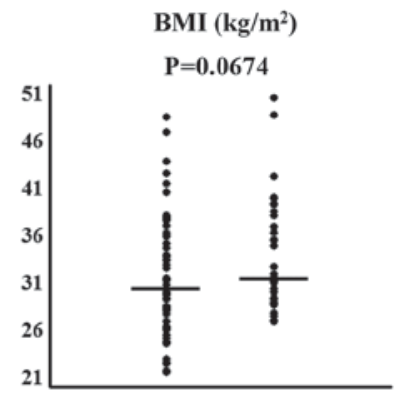

LDL $(\mathrm{mg} / \mathrm{dl})$

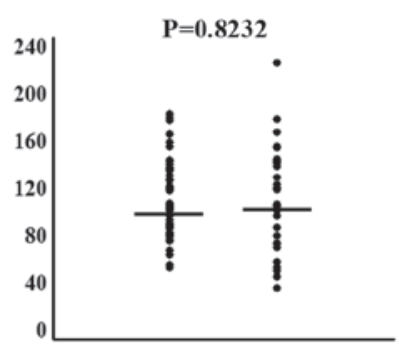

Telomerase activity (AU) $\mathrm{P}=\mathbf{0 . 0 2 6 1}$

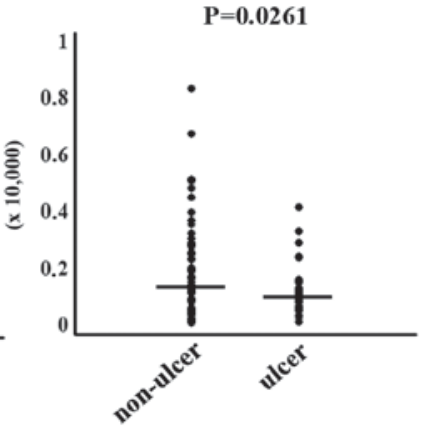

Figure 1. Scatter plots showing all values of clinical parameters investigated in this study for the non-ulcer and ulcer group of T2DM patients. In each graph, dots represent distinct values and horizontal line represents the mean or median, depending on the normality or not of the distribution, respectively. T2DM, type 2 diabetes mellitus; BMI, body mass index; TC, total cholesterol; TG, triglycerides; HDL, high-density lipoprotein; LDL, low-density lipoprotein; NDS, neuropathy disability score; AU, arbitrary units. 
By contrast, the ongoing Framingham Heart Study has demonstrated a statistically significant relationship between insulin resistance, oxidative stress, hypertension and telomere length reduction in males (28). However, even though telomerase activity has been often associated with diabetes and some of its complications, a correlation with diabetic ulcers has not been shown thus far (29).

In the current study, we showed that diabetic patients with ulcers present lower telomerase activity in their leukocytes than patients without ulcers irrespective of the disease duration. A decreased leukocyte telomere length and telomerase activity in T2DM patients has been also reported previously (30). In addition, the telomere length can be used as an indicator of hyperglycemia and hyperinsulinemia (17-21,23-25,31-34). Using a sample of T2DM adult men, Murillo-Ortiz et al showed that telomere shortening increases with the duration of diabetes, suggesting that the progressive increase in inflammation has an additive direct effect on telomere shortening (35). In addition, telomere length has been shown to be a reliable marker for the prognosis of diabetic kidney disease progression (19) and for retinal endothelial cell senescence $(36,37)$.

Furthermore, we showed that ulcer-bearing T2DM patients were characterized by greater waist circumference and NDS, suggesting a possible interrelationship of these parameters in the clinical outcome of diabetes mellitus. Nevertheless, if patients of this study were segregated based on their NDS, no statistically significant difference of leukocyte telomerase activity was observed between the neuropathy and no neuropathy groups (data not shown).

Thus, our findings may pinpoint to the presence of some common clinical traits in diabetic patients with ulcer, but caution should be taken in the translation and extrapolation of the results due to certain limitations of the study: i) Patient group size is relatively small and thus the study needs to be extended in order to validate our data in larger populations; and ii) a great intra- and inter-group diversity exists in terms of drug treatment for diabetes itself, as well as for existing comorbidities, which may interfere with the measured clinical characteristics. Telomere length, for example, has been reported to be negatively affected by drugs $(38,39)$ and telomerase activity increases with paracetamol administration in rat embryonic liver cells (40).

In conclusion, we have demonstrated that the patients with diabetic ulcers had higher waist circumference and NDS, along with lower leukocyte telomerase activity. Confirmation of these results in a larger patient group could further contribute to the understanding of T2DM pathophysiology.

\section{Competing interests}

Demetrios A. Spandidos is the Editor-in-Chief for the journal, but had no personal involvement in the reviewing process, or any influence in terms of adjudicating on the final decision, for this article.

\section{References}

1. Elks CE and Scott RA: The long and short of telomere length and diabetes. Diabetes 63: 65-67, 2014.
2. Harley $\mathrm{CB}$, Futcher $\mathrm{AB}$ and Greider CW: Telomeres shorten during ageing of human fibroblasts. Nature 345: 458-460, 1990.

3. Slagboom PE, Droog S and Boomsma DI: Genetic determination of telomere size in humans: A twin study of three age groups. Am J Hum Genet 55: 876-882, 1994.

4. von Zglinicki T and Martin-Ruiz CM: Telomeres as biomarkers for ageing and age-related diseases. Curr Mol Med 5: 197-203, 2005.

5. Petersen S, Saretzki G and von Zglinicki T: Preferential accumulation of single-stranded regions in telomeres of human fibroblasts. Exp Cell Res 239: 152-160, 1998.

6. Matthews C, Gorenne I, Scott S, Figg N, Kirkpatrick P, Ritchie A, Goddard M and Bennett M: Vascular smooth muscle cells undergo telomere-based senescence in human atherosclerosis: Effects of telomerase and oxidative stress. Circ Res 99: 156-164, 2006.

7. Hansel B, Giral P, Nobecourt E, Chantepie S, Bruckert E, Chapman MJ and Kontush A: Metabolic syndrome is associated with elevated oxidative stress and dysfunctional dense highdensity lipoprotein particles displaying impaired antioxidative activity. J Clin Endocrinol Metab 89: 4963-4971, 2004.

8. Ilie AC, Alexa ID, Moroşanu AI, Covic A and Cepoi V: Effects of oxidative stress and pharmacological treatment on geriatric syndromes in the hospitalized elderly patients. Farmacia 64: 588-593, 2016.

9. Totan A, Greabu M, Mitrea M, Mohora M and Arsene AL: Relationships between erythrocyte $\mathrm{Na}^{+} / \mathrm{K}^{+}$-ATPase activity, oxidative stress and high blood pressure in hypertensive diabetic patients. Farmacia 58: 322-331, 2010.

10. Tzanetakou IP, Katsilambros NL, Benetos A, Mikhailidis DP and Perrea DN: 'Is obesity linked to aging?': Adipose tissue and the role of telomeres. Ageing Res Rev 11: 220-229, 2012.

11. Ghibu S, Ilie I, Mureșan A and Mogoșan C: Perspectives in the experimental study of the metabolic syndrome. Farmacia 63: 482-486, 2015.

12. Gardner JP, Li S, Srinivasan SR, Chen W, Kimura M, Lu X, Berenson GS and Aviv A: Rise in insulin resistance is associated with escalated telomere attrition. Circulation 111: 2171-2177, 2005.

13. Cherkas LF, Hunkin JL, Kato BS, Richards JB, Gardner JP, Surdulescu GL, Kimura M, Lu X, Spector TD and Aviv A: The association between physical activity in leisure time and leukocyte telomere length. Arch Intern Med 168: 154-158, 2008.

14. Kuhlow D, Florian S, von Figura G, Weimer S, Schulz N, Petzke KJ, Zarse K, Pfeiffer AF, Rudolph KL and Ristow M: Telomerase deficiency impairs glucose metabolism and insulin secretion. Aging (Albany NY) 2: 650-658, 2010.

15. Serra V, Grune T, Sitte N, Saretzki G and von Zglinicki T: Telomere length as a marker of oxidative stress in primary human fibroblast cultures. Ann N Y Acad Sci 908: 327-330, 2000.

16. Salpea KD, Talmud PJ, Cooper JA, Maubaret CG, Stephens JW, Abelak K and Humphries SE: Association of telomere length with type 2 diabetes, oxidative stress and UCP2 gene variation. Atherosclerosis 209: 42-50, 2010.

17. Zhao J, Miao K, Wang H, Ding H and Wang DW: Association between telomere length and type 2 diabetes mellitus: A metaanalysis. PLoS One 8: e79993, 2013.

18. Sharma R, Gupta A, Thungapathra M and Bansal R: Telomere mean length in patients with diabetic retinopathy. Sci Rep 5: $18368,2015$.

19. Fyhrquist F, Tiitu A, Saijonmaa O, Forsblom C and Groop PH; FinnDiane Study Group: Telomere length and progression of diabetic nephropathy in patients with type 1 diabetes. J Intern Med 267: 278-286, 2010.

20. Dudinskaya EN, Tkacheva ON, Shestakova MV, Brailova NV, Strazhesko ID, Akasheva DU, Isaykina OY, Sharashkina NV, Kashtanova DA and Boytsov SA: Short telomere length is associated with arterial aging in patients with type 2 diabetes mellitus. Endocr Connect 4: 136-143, 2015.

21. Boulton A: The diabetic foot: The diabetic foot: Epidemiology, risk factors and epidemiology, risk factors and the status of care. Diabetes Voice 50: 5-7, 2005.

22. Lu B, Yang Z, Wang M, Yang Z, Gong W, Yang Y, Wen J, Zhang Z, Zhao N, Zhu X and Hu R: High prevalence of diabetic neuropathy in population-based patients diagnosed with type 2 diabetes in the Shanghai downtown. Diabetes Res Clin Pract 88: 289-294, 2010. 
23. Baltzis D, Roustit M, Grammatikopoulou MG, Katsaboukas D, Athanasiou V, Iakovou I, Veves A, Manes C and Trakatelli MC: Diabetic peripheral neuropathy as a predictor of asymptomatic myocardial ischemia in type 2 diabetes mellitus: A crosssectional study. Adv Ther 33: 1840-1847, 2016.

24. American Diabetes Association: Standards of medical care in diabetes-2015 abridged for primary care providers. Clin Diabetes 33: 97-111, 2015.

25. Pham H, Armstrong DG, Harvey C, Harkless LB, Giurini JM and Veves A: Screening techniques to identify people at high risk for diabetic foot ulceration: A prospective multicenter trial. Diabetes Care 23: 606-611, 2000.

26. Barg FK, Cronholm PF, Easley EE, Davis T, Hampton M, Malay DS, Donohue C, Song J, Thom SR and Margolis DJ: A qualitative study of the experience of lower extremity wounds and amputations among people with diabetes in Philadelphia. Wound Repair Regen 25: 864-870, 2017.

27. Vidacek NS, Nanic L, Ravlic S, Sopta M, Geric M, Gajski G, Garaj-Vrhovac V and Rubelj I: Telomeres, nutrition, and longevity: Can we really navigate our aging? J Gerontol A Biol Sci Med Sci 73: 39-47, 2017.

28. Demissie S, Levy D, Benjamin EJ, Cupples LA, Gardner JP, Herbert A, Kimura M, Larson MG, Meigs JB, Keaney JF and Aviv A: Insulin resistance, oxidative stress, hypertension, and leukocyte telomere length in men from the Framingham Heart Study. Aging Cell 5: 325-330, 2006.

29. Qi Nan W, Ling Z and Bing C: The influence of the telomeretelomerase system on diabetes mellitus and its vascular complications. Expert Opin Ther Targets 19: 849-864, 2015.

30. Ma D, Yu Y, Yu X, Zhang M and Yang Y: The changes of leukocyte telomere length and telomerase activity after sitagliptin intervention in newly diagnosed type 2 diabetes. Diabetes Metab Res Rev 31: 256-261, 2015.

31. Verberne HJ, Acampa W, Anagnostopoulos C, Ballinger J, Bengel F, De Bondt P, Buechel RR, Cuocolo A, van Eck-Smit BL, Flotats A, et al; European Association of Nuclear Medicine (EANM): EANM procedural guidelines for radionuclide myocardial perfusion imaging with SPECT and SPECT/CT: 2015 revision. Eur J Nucl Med Mol Imaging 42: 1929-1940, 2015.

32. Wackers FJ, Young LH, Inzucchi SE, Chyun DA, Davey JA, Barrett EJ, Taillefer R, Wittlin SD, Heller GV, Filipchuk N, et al: Detection of silent myocardial ischemia in asymptomatic diabetic subjects: The DIAD study. Diabetes Care 27: 1954-1961, 2004.
33. Tesfaye S, Chaturvedi N, Eaton SE, Ward JD, Manes C, IonescuTirgoviste C, Witte DR and Fuller JH; EURODIAB Prospective Complications Study Group: Vascular risk factors and diabetic neuropathy. N Engl J Med 352: 341-350, 2005.

34. Pop-Busui R, Evans GW, Gerstein HC, Fonseca V, Fleg JL, Hoogwerf BJ, Genuth S, Grimm RH, Corson MA and Prineas R; Action to Control Cardiovascular Risk in Diabetes Study Group: Effects of cardiac autonomic dysfunction on mortality risk in the Action to Control Cardiovascular Risk in Diabetes (ACCORD) trial. Diabetes Care 33: 1578-1584, 2010.

35. Murillo-Ortiz B, Albarrán-Tamayo F, Arenas-Aranda D, BenítezBribiesca L, Malacara-Hernández JM, Martínez-Garza S, Hernández-González M, Solorio S, Garay-Sevilla ME and Mora-Villalpando C: Telomere length and type 2 diabetes in males, a premature aging syndrome. Aging Male 15: 54-58, 2012.

36. Honda S, Weigel A, Hjelmeland LM and Handa JT: Induction of telomere shortening and replicative senescence by cryopreservation. Biochem Biophys Res Commun 282: 493-498, 2001.

37. Matsunaga H,Handa JT, Aotaki-Keen A, Sherwood SW, West MD and Hjelmeland LM: Beta-galactosidase histochemistry and telomere loss in senescent retinal pigment epithelial cells. Invest Ophthalmol Vis Sci 40: 197-202, 1999.

38. Yang Z, Ye J, Li C, Zhou D, Shen Q, Wu J, Cao L, Wang T, Cui D, $\mathrm{He} \mathrm{S}$, et al: Drug addiction is associated with leukocyte telomere length. Sci Rep 3: 1542, 2013.

39. Imam T, Jitratkosol MH, Soudeyns H, Sattha B, Gadawski I, Maan E, Forbes JC, Alimenti A, Lapointe N, Lamarre V, et al; CIHR Emerging Team Grant on HIV Therapy and Aging: CARMA: Leukocyte telomere length in HIV-infected pregnant women treated with antiretroviral drugs during pregnancy and their uninfected infants. J Acquir Immune Defic Syndr 60: 495-502, 2012.

40. Bader A, Petters O, Keller M and Pavlica S: Paracetamol treatment increases telomerase activity in rat embryonic liver cells. Pharmacol Rep 63: 1435-1441, 2011.

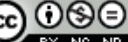

This work is licensed under a Creative Common Attribution-NonCommercial-NoDerivatives 4.0 International (CC BY-NC-ND 4.0) License. 